\title{
Cationic Ring Opening Copolymerization of 1,3-Dioxolane with Styrene by Montmorillonite Maghnite- $\mathrm{H}^{+}$Catalyst
}

\section{NABIL HAMAM*, MOHAMMED ISSAM FERRAHI and MOHAMMED BELBACHIR}

Polymer Chemistry Laboratory, Department of Chemistry, Faculty of Accurate and Applied Science, University of Oran 1 Ahmed Ben Bella BP N ${ }^{\circ} 1524$ El M'Naouar, 31000 Oran, Algeria.

${ }^{\star}$ Corresponding author E-mail: nabilpolymere@ hotmail.fr

http://dx.doi.org/10.13005/ojc/320305

(Received: August 18, 2015; Accepted: September 28, 2015)

\begin{abstract}
In the present work, the copolymerization of 1,3-Dioxolane (DXL) with Styrene (St) catalyzed by Maghnite- $\mathrm{H}+$ a montmorillonite sheet silicate clay exchanged with protons, was investigated. The cationic ring opening polymerization was initiated by Maghnite- $\mathrm{H}+$ in bulk. The copolymer obtained was characterized by $1 \mathrm{H}-\mathrm{NMR}, \mathrm{DSC}$ and IR spectroscopy. The studies done, such as the effect of the amount of catalyser on the syntheses of poly (DXL-co- Styrene).
\end{abstract}

Keywords: Copolymerization, Montmorillonite Maghnite- $\mathrm{H}^{+}$Catalyst, DXL.

\section{INTRODUCTION}

Clay minerals, a large family of aluminosilicate structures with a range of chemical composition, structure and surface properties, are very reactive materials due to their small grain size large surface area, adsorption properties and chemical variability ${ }^{1}$. The reactions catalyzed by Clay minerals montmorillonite are usually carried out under mild conditions with high yields and high selectivity, and the workup of these reactions is very simple; only filtration to remove the catalyst and evaporation of the solvent are required. Montmorillonite catalysts are easily recovered and reused $^{2}$.
Increasing environmental concerns in recent years have resulted in a demand for more effective catalytic processes. In this regard, studies have been carried out on the development of solid acids, such as "Keggin-type Heteropoly compounds" ${ }^{3}$ or acidic clays ${ }^{4}$, to replace aggressive and dangerous homogeneous acids to overcome the problems of separating the catalyst from the products and the disposal of solid/liquid wastes.

Recently, monomers were found to intercalate into lattice layers of montmorillonite clay, permitting in situ polymerizations yielding polymer/clay nano- composites. Several polymers, for example, polystyrene (PS) ${ }^{5}$, and polystyrene-block- 
polyisoprene-block-polystyrene ${ }^{6}$, an Algerian proton exchanged montmorillonite clay called Maghnite- $\mathrm{H}_{+}$ (Mag- $\mathrm{H}+)$, a new nontoxic cationic initiator, was used as a catalyst for cationic polymerization of a number of vinylic and heterocyclic monomers ${ }^{7-8}$.

The purpose of this paper is to study the copolymerization of DXL with Styrene, catalyzed by Maghnite- $\mathrm{H}^{+}$a proton exchanged Montmorillonite clay $^{7}$. The effects of the amounts of the Maghnite- $\mathrm{H}^{+}$ on the synthesis of poly (DXL-co-Styrene) are also discussed.

Techniques such as Infra Red (IR), Differential Scanning Calorimetry (DSC), Hydrogen and Proton Nuclear Magnetic Resonance (1H NMR), were used to characterize the products of the reaction.

\section{EXPERIMENTAL}

Styrene (grade 99\%) was used as purchased from Aldrich. 1,3-Dioxolane (DXL) was distilled over the blue benzophenone-Na complex.Chloroform was dried on $\mathrm{CaH}_{2}$ anhydrous and distilled before use. Raw-Maghnite: Algerian Montmorillonite clay was procured from BENTAL (Algerian Society of Bentonite).

\section{Preparation of "Maghnite- $\mathbf{H}^{+} \mathbf{0 . 2 5 M "}$}

Maghnite- $\mathrm{H}^{+}$was prepared according to the process reported in our previous study ${ }^{8}$. RawMaghnite $(20 \mathrm{~g})$ was crushed for $20 \mathrm{mn}$ using a prolabo ceramic balls grinder. It was then dried for 2 hours at $105^{\circ} \mathrm{C}$ the Maghnite was placed in an Erlenmeyer flask together with $500 \mathrm{ml}$ of distilled water. The Maghnite/water mixture was stirred using a magnetic stirrer and combined with $0.25 \mathrm{M}$ sulfuric acid solution, until saturation was achieved over 2 days at room temperature, the mineral was then washed with distilled water to became sulfate free and then dried at $105^{\circ} \mathrm{C}$, a test of the barium nitrate of the residue of rinsing water is needed to ensure that the sulfate is eliminated.

\section{Copolymerization and products characterization}

In a $50 \mathrm{ml}$ beaker, DXL (11.7 mol/l) and Styrene $(6.3 \mathrm{~mol} / \mathrm{l})$ were dissolved in $20 \mathrm{ml}$ of Chloroform and a chosen amount of Maghnite- $\mathrm{H}^{+}$ was added at $40^{\circ} \mathrm{C}$. The weight ratio was kept constant in all flasks. After the required time was reached, an aliquot of the reaction mixture was then removed in such a manner as to exclude any clay mineral, and then dried by evaporation to remove solvent and remaining monomer.

\section{RESULTS AND DISCUSSIONS}

The results of experiments of DXL with Styrene Copolymerization induced by Maghnite- $\mathrm{H}^{+}$

Table 1: Copolymerizations of 1,3-Dioxolane with styrene using different amount of Maghnite- $\mathrm{H}^{+}$

\begin{tabular}{lcc}
\hline Experiment & $\begin{array}{c}\text { Maghnite- } \mathbf{H}^{+} \\
(\mathbf{0 . 2 5 \%} \mathbf{M})\end{array}$ & $\begin{array}{c}\text { Yield } \\
\%\end{array}$ \\
\hline 1 & 10 & 39.56 \\
2 & 5.0 & 19.23 \\
3 & 2.5 & 10.13 \\
\hline
\end{tabular}

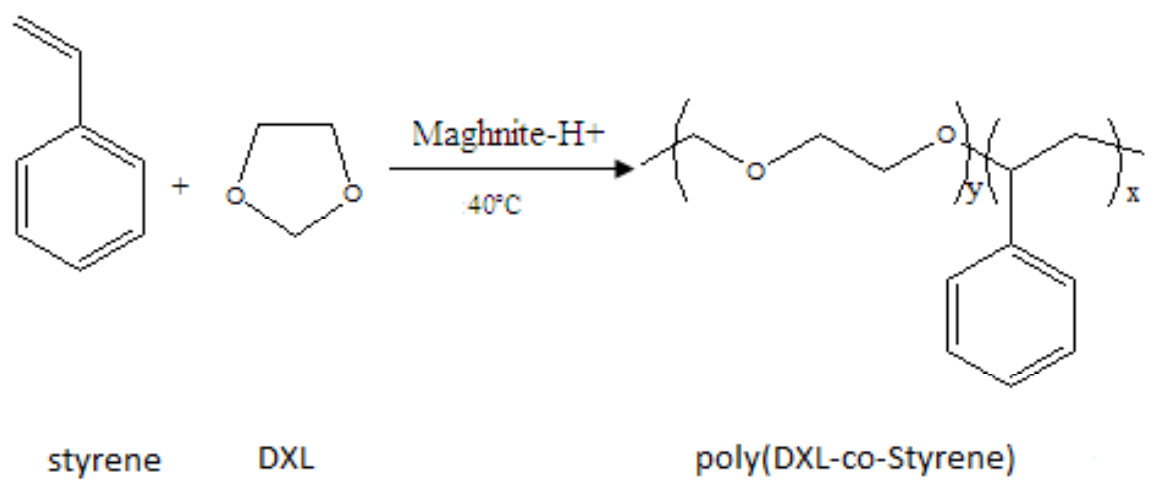

Fig. 1: Synthesis of poly (DXL -co- Styrene) by Maghnite- $\mathrm{H}^{+}$catalyst 


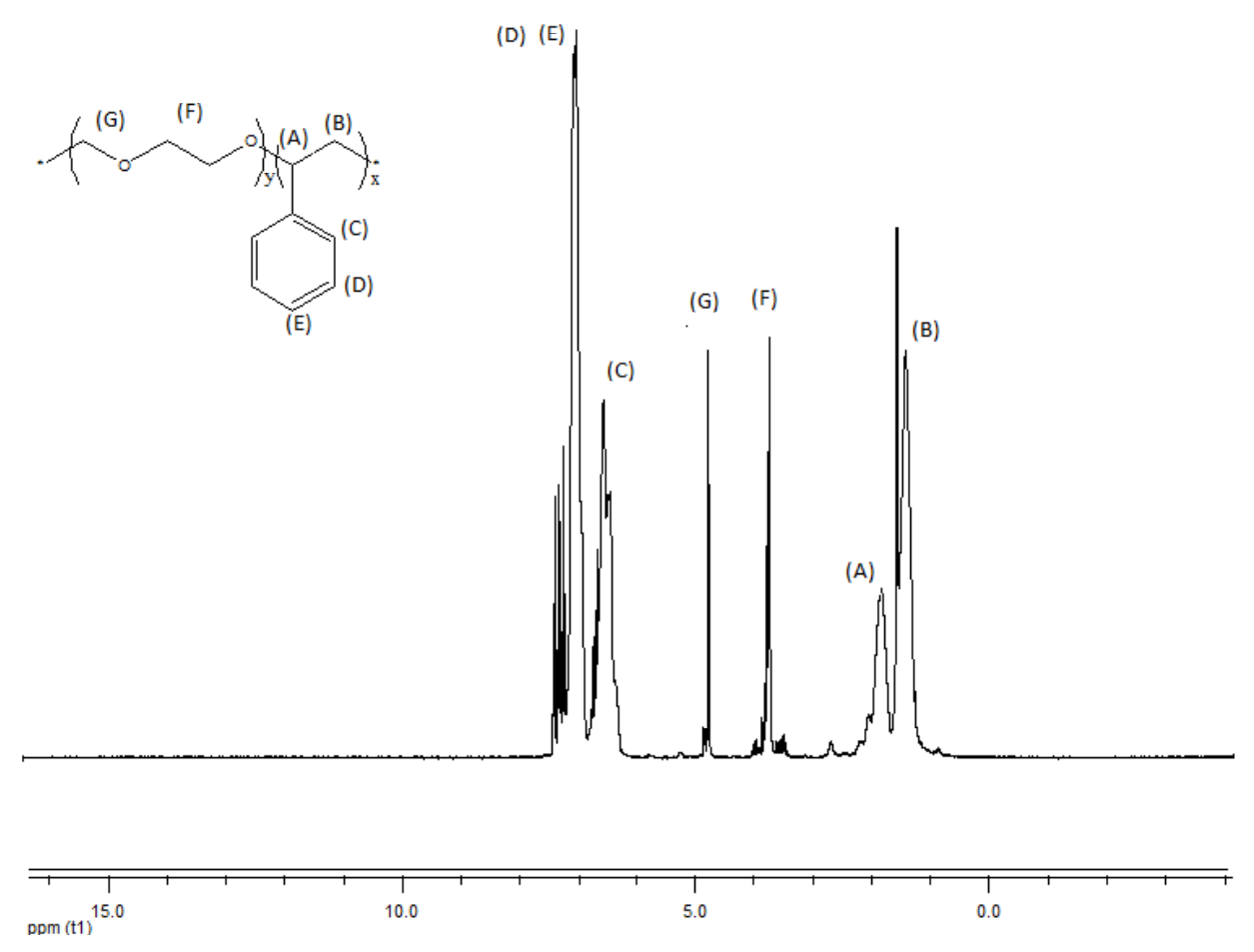

Fig. 2: ${ }^{1} \mathrm{H}$ NMR spectrum of poly (DXL-co-Styrene) in $\mathrm{CDCl3}$

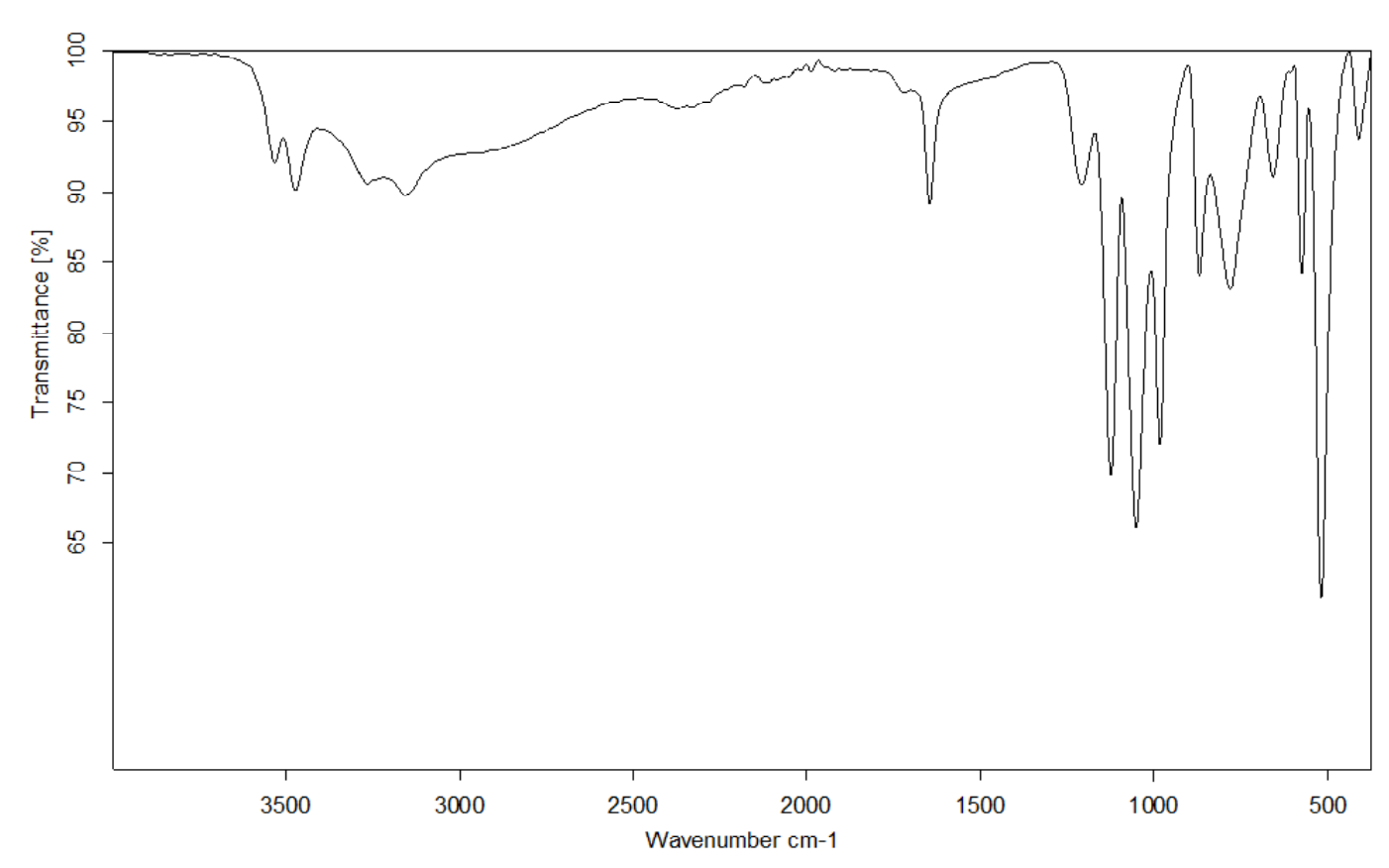

Fig. 3: IR spectrum of poly (DXL-co- Styrene) 


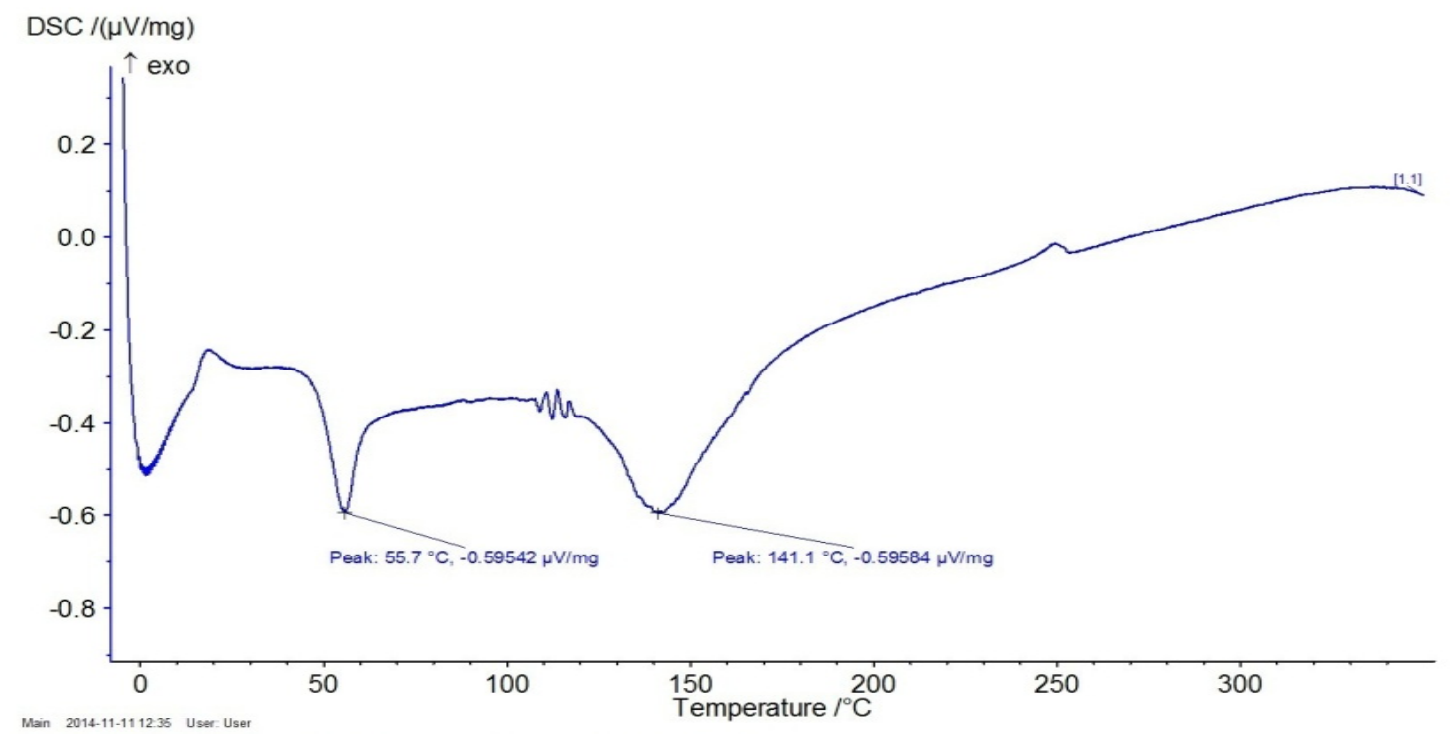

Fig. 4: DSC thermogram of poly (DXL-co- Styrene)

$0.25 \mathrm{M}$ proceed in bulk are reported in (Table 1). For all these experiments the temperature was kept constant at $40^{\circ} \mathrm{C}$ for 12 hours.

\section{Effect of the amount of Maghnite- $\mathrm{H}^{+}$on the copolymerization}

We can see from (Table 1) that the yield increases as the proportion of Maghnite- $\mathrm{H}^{+} 0.25$ $M$ increases (experiments 1,2). Shows the effect of the amount of Maghnite- $\mathrm{H}+$ on the polymerization yield. Indeed, using various amounts: $2.5,5$ and $10 \%$ by weight, the polymerization was carried out in bulk at $40^{\circ} \mathrm{C}$. The copolymerization yield increased with the amount, thus clearly showing the effect of Maghnite- $\mathrm{H}^{+}$as a catalyst. This phenomenon is probably the result of an increase in the number of "initiating active sites" responsible of inducing polymerization, a number that is pro rata to the amount of catalyst used in reaction.

\section{Characterization of products}

According to the work published by Masahiko Okada ${ }^{10}$ the polymer obtained was characterized by $300 \mathrm{MHz} 1 \mathrm{H}-\mathrm{NMR}$ in CDCl3. (Figure 2) shows the chemical shifts at $7.23 \mathrm{ppm}$ and $7.33 \mathrm{ppm}$ for the protons of benzene ring, that at $3.74 \mathrm{ppm}$ for the protons of methylene groups and that at $4.8 \mathrm{ppm}$ for the protons of ethylene group of
Poly DXL and those at $1.26 \mathrm{ppm}$ and $1.74 \mathrm{ppm}$ for the methylene and methine groups of Poly St.

IR spectroscopy (Figure 3) allows us to confirm the nature of the polymer by identifying, The phenyl of St appears in three absorption bands: one at $1645.77 \mathrm{~cm}^{-1}$ for the $(\mathrm{C}=\mathrm{C})$, another at 3157.29 $\mathrm{cm}^{-1}$ for $(\mathrm{CH})$ and the last at $781.10 \mathrm{~cm}^{-1}$ for the deformation in the plan of $(\mathrm{CH})$. The ether function appears clearly at $1051.42 \mathrm{~cm}^{-1}$. The large band at $3473.29 \mathrm{~cm}^{-1}$ is attributed to the connection $(\mathrm{OH})$, which is probably due to a bad drying of $\mathrm{KBr}$ used for this analysis.

The study of polymers degradation (Figure 4) can most often intervene on the factors which improve their thermal stability and also which allow to situate better their own domain of application.DSC analysis of the polymer to give a glass transition temperature obtained at $55.7^{\circ} \mathrm{C}$ and a melting temperature at $141.1^{\circ} \mathrm{C}$, the presence of both the transition temperature and the melting temperature, shows that the polymer is semi crystalline.

\section{CONCLUSIONS}

In conclusion, we have found that acidexchanged Maghnite- $\mathrm{H}^{+}$is effective as acidic catalyst 
for the preparation of poly (DXL -co- Styrene). The studies done such as the effect of the amount of catalyst on the syntheses of polymer. The polymerization proceeds smoothly by a very simple procedure, and a simple filtration is sufficient to recover the catalyst.

\section{REFERENCES}

1. Caglar, B. ; Afsin,B .; Tabak, E.;Eren,E. 5. Chemical. Engineering .Journal. 2009, 149,242-248.

2. Brown, D.R.; Carpathica, G. Clays as catalyst and reagent supports. Ser.Clays .1994, 45, 45.

3. Wang, P.; Jia, Z.;Zhao, M.;Sun, Z.; Zhang, H.; Ji, S. ; Zhao, Y. J. Chem. Ind. Eng. Soc. China. 2009,7: 12.

4. Donald, R.; John, F. US Patent.1993, 5262562.
Vu Moc, T.; Petit, H .; Maitte, P. Bull. Soc. Belg. 1982, 91, 261.

6. Vu Moc, T.; Petit, H . ; Maitte, P. Bull. Soc. Belg. 1982, 91, 261

7. Ferrahi, M.I. ; Belbachir, M. Int. J. Mol. Sci, 2003, 4, 312.

8. Belbachir, M.; Bensaoula, A. US Patent.2001,6, 274,527B1.

9. Yahyaoui, A.; Belbachir, M. ; Hachemaoui,A. ,Int. J. Mol. Sci. 2003, 4, 572.

10. Okada,M.; Yamashita,Y.; Ishii,Y. Die. Makromolekulare .Chemie,1966, 94, 1,181193. 